\title{
Synthesis and characterization of silver/montmorillonite/ chitosan bionanocomposites by chemical reduction method and their antibacterial activity
}

This article was published in the following Dove Press journal:

International Journal of Nanomedicine

26 January 2011

Number of times this article has been viewed

\author{
Kamyar Shameli' \\ Mansor Bin Ahmad' \\ Mohsen Zargar ${ }^{3}$ \\ Wan Md Zin Wan Yunus' \\ Nor Azowa Ibrahim' \\ Parvaneh Shabanzadeh ${ }^{2}$ \\ Mansour Ghaffari \\ Moghaddam ${ }^{4}$ \\ 'Department of Chemistry, Faculty \\ of Science, ${ }^{2}$ Institute for Mathematical \\ Research, Universiti Putra Malaysia, \\ Selangor, Malaysia; ${ }^{3}$ Department of \\ Biology, Islamic Azad University, \\ Qum, Iran; ${ }^{4}$ Department of Chemistry, \\ Faculty of Science, University of \\ Zabol, Zabol, Iran
}

Correspondence: Kamyar Shameli Department of Chemistry, Faculty of Science, Universiti Putra Malaysia, 43400, Serdang, Selangor, Malaysia Tel +60389466044

Fax +60389466043

Email kamyarshameli@gmail.com

\begin{abstract}
Silver nanoparticles (AgNPs) of a small size were successfully synthesized using the wet chemical reduction method into the lamellar space layer of montmorillonite/ chitosan (MMT/Cts) as an organomodified mineral solid support in the absence of any heat treatment. $\mathrm{AgNO}_{3}$, MMT, Cts, and $\mathrm{NaBH}_{4}$ were used as the silver precursor, the solid support, the natural polymeric stabilizer, and the chemical reduction agent, respectively. MMT was suspended in aqueous $\mathrm{AgNO}_{3} / \mathrm{Cts}$ solution. The interlamellar space limits were changed (d-spacing $=1.24-1.54 \mathrm{~nm}$ ); therefore, AgNPs formed on the interlayer and external surface of MMT/Cts with d-average $=6.28-9.84 \mathrm{~nm}$ diameter. Characterizations were done using different methods, ie, ultraviolet-visible spectroscopy, powder X-ray diffraction, transmission electron microscopy, scanning electron microscopy, energy dispersive X-ray fluorescence spectrometry, and Fourier transform infrared spectroscopy. Silver/montmorillonite/chitosan bionanocomposite (Ag/MMT/Cts BNC) systems were examined. The antibacterial activity of AgNPs in MMT/Cts was investigated against Gram-positive bacteria, ie, Staphylococcus aureus and methicillin-resistant S. aureus and Gram-negative bacteria, ie, Escherichia coli, E. coli $\mathrm{O} 157: \mathrm{H7}$, and Pseudomonas aeruginosa by the disc diffusion method using Mueller Hinton agar at different sizes of AgNPs. All of the synthesized Ag/MMT/Cts BNCs were found to have high antibacterial activity. These results show that Ag/MMT/Cts BNCs can be useful in different biological research and biomedical applications, including surgical devices and drug delivery vehicles.
\end{abstract}

Keywords: silver nanoparticles, bionanocomposites, montmorillonite, chitosan, antibacterial activity, Mueller Hinton agar

\section{Introduction}

In recent years, silver nanoparticles (AgNPs) have attracted considerable attention for medical and chemical applications due to their exceptional properties, including antibacterial activity, high resistance to oxidation, and high thermal conductivity. ${ }^{1-5}$ Recently, different inorganic antibacterial materials, including AgNPs, have been expanded and some are in commercial use. ${ }^{6}$ The antibacterial activity of AgNPscontaining materials can be used, for example, in medicines to treat infections in human skin,,${ }^{7,8}$ dental materials, ${ }^{9}$ catheters, ${ }^{10,11}$ vascular grafts, ${ }^{12}$ stainless steel materials, ${ }^{13}$ arthroplasty, ${ }^{14}$ and burn treatment, ${ }^{15,16}$ as well as to prevent microorganism colonization on prostheses. ${ }^{17}$ In addition, nanomaterials including AgNPs can be utilized for water treatment ${ }^{18}$ and also for reducing bacteria on textile fabrics. ${ }^{19,20}$ AgNPs also have effective cytoprotective activity towards human immunodeficiency virus-infected cells. ${ }^{21}$ Because of this broad variety of applications, many preparation methods have 
been developed. In addition to the bactericidal effects of $\mathrm{Ag}^{+}$ ions, the antimicrobial activity of colloid AgNPs is influenced by the size of the particles, ie, the smaller the particles, the greater the antimicrobial effect. ${ }^{22-28}$ Therefore, in developing methods for AgNP preparation, it is important to control the size of the AgNP particles. AgNPs of small size and devoid of aggregation properties are favorable for this purpose.

Chemical reduction methods have been widely investigated for the synthesis of AgNPs because these techniques can be executed under easy and gentle conditions, and can be used to synthesize AgNPs on a large scale. The reducing capability of a reductant has a significant role in the synthesis of AgNPs by the reduction reaction. The use of a strong reducing agent, such as $\mathrm{NaBH}_{4}$, results in tiny particles that are well dispersed. ${ }^{29}$

Nowadays, a succession of chemical reductants can been used for the synthesis of noble metal nanoparticles which contain $\mathrm{NaBH}_{4},{ }^{30,31,36} \mathrm{NH}_{2} \mathrm{OH},{ }^{32} \mathrm{~N}_{2} \mathrm{H}_{4},{ }^{33,36}\left(\mathrm{CH}_{3}\right)_{2}$ $\mathrm{NH} \cdot \mathrm{BH}_{3},{ }^{34} \mathrm{H}_{2},{ }^{35}$ formaldehyde, ${ }^{36}$ formamide, ${ }^{37}$ Tollens' reagents, ${ }^{38}$ ethylene glycol, ${ }^{39}$ ethanol, ${ }^{40}$ citrate,,${ }^{32,40}$ aniline, ${ }^{41}$ polyaniline, ${ }^{42}$ or ascorbic acid. ${ }^{43}$

Layered silicates, eg, montmorillonite (MMT), have been used in polymer nanocomposites with a significant improvement in mechanical properties. ${ }^{44,45}$ MMT possesses a 2-to-1 layered structure with a single octahedral aluminum layer located between two layers of tetrahedral silicon. ${ }^{46}$ Each layer is about $1 \mathrm{~nm}$ thick with a lateral dimension of 100-1000 nm. ${ }^{47}$ Furthermore, being a lamellar clay, MMT has intercalation, swelling, and ion exchange properties. ${ }^{48}$ MMT can be delaminated into elemental sheets without difficulty. Therefore, it is tempting to utilize these sheets as the substrate for preparation of nanoscale metals by means of electrodeless plating. The MMT interlayer space has been used for the synthesis of material and biomaterial nanoparticles as the support for anchoring transition metal complexes and as adsorbents for cationic ions. ${ }^{49,50}$

Among the natural polymers, chitosan (Cts) has been extensively investigated as a natural cationic biopolymer because of its excellent biocompatibility, biodegradability, nontoxicity, bioactivity, and multifunctional groups, as well as its solubility in aqueous medium for food packaging film, bone substitutes, and artificial skin. ${ }^{51} \mathrm{Cts}$ can be intercalated in MMT by cationic exchange and hydrogen bonding processes, whereby the resulting bionanocomposites (BNCs) show interesting structural and functional properties. ${ }^{52}$ Conversely, BNCs are made of a natural polymeric matrix and inorganic/organic filler with at least one dimension on the nanometer scale. Metal/clay/polymer compounds like BNCs with their excellent properties have become a promising new areas of research. ${ }^{53}$

Furthermore, AgNPs have long been known to have strong inhibitory and bactericidal effects, as well as a broad spectrum of antimicrobial activity, and have been used for centuries to prevent and treat a variety of diseases, most notably infections. AgNPs were reported recently as having antibacterial activity against Escherichia coli, Staphylococcus aureus, methicillin-resistant Staphylococcus epidermis, and methicillin-resistant $S$. aureus (MRSA) bacteria. ${ }^{53-55}$ AgNPs also exhibit potent cytoprotective activity towards cells infected with human immunodeficiency virus. ${ }^{56}$ The application of AgNPs for biological labelling in neuroblastoma cells was recently reported. Due to the strong plasmonresonant properties of AgNPs and the enhanced resolution obtainable with high-illumination systems in physiological solution, studies of the interactions between AgNPs and human cells have been possible. ${ }^{57}$ Hence, similar studies on Ag/poly(lactic acid), ${ }^{30} \mathrm{Ag} / \mathrm{MMT},{ }^{48,59} \mathrm{Ag} /$ talc,${ }^{58} \mathrm{Ag} / \mathrm{MMT} /$ starch $\mathrm{BNCs}^{60}$ and $\mathrm{Ag} / \mathrm{MMT} / \mathrm{Cts} \mathrm{BNCs},{ }^{61,62}$ have been undertaken previously.

In this research, the spherical structure of AgNPs was synthesized in the interlayer surface of the MMT layers modified with a low percentage of $\mathrm{Cts}$ in aqueous solution by using $\mathrm{AgNO}_{3}, \mathrm{Cts}$, and $\mathrm{NaBH}_{4}$ as the silver precursor, the stabilizer, and the reduction agent, respectively, at room temperature. We used modified clay (MMT/Cts) as the protective colloid to prevent the AgNPs from aggregating, and it was found that MMT/Cts also assisted in the chemical reduction process of silver. Needless to say, to date, there has not been any report of a study of Ag/MMT/Cts BNCs using a chemical reduction method, ie, lamellar polymeric silicate, which is the subject of this research. In addition, the antibacterial activity of $\mathrm{AgNO}_{3} / \mathrm{MMT} / \mathrm{Cts}$ and $\mathrm{Ag} / \mathrm{MMT} / \mathrm{Cts} \mathrm{BNCs}$ were investigated and compared. Using this method, we were able to obtain AgNPs of different sizes and dissimilar antibacterial activity by controlling the $\mathrm{AgNO}_{3}$ concentration.

\section{Materials and methods Chemicals}

All reagents in this work were of analytical grade and used as received without further purification. $\mathrm{AgNO}_{3}(99.98 \%)$, used as the silver precursor, was obtained from Merck (Darmstadt, Germany). Meanwhile, the MMT powder, used as a solid support for the AgNPs, was purchased from Kunipia-F (Tokyo, Japan). $\mathrm{NaBH}_{4}$ (98.5\%), low-molecular-weight Cts, and glacial acetic acid (99\%) used as a reduction agent, a stabilizer, and for solubilizing $\mathrm{Cts}$, respectively, were obtained from 
Sigma-Aldrich (St Louis, MO). All the aqueous solutions were used with double-distilled water.

\section{Synthesis of $\mathrm{Ag} / \mathrm{MMT} / \mathrm{Cts}$ BNCs using $\mathrm{NaBH}_{4}$}

For the synthesis of $\mathrm{Ag} / \mathrm{MMT} / \mathrm{Cts} \mathrm{BNCs}$, soluble Cts $(100 \mathrm{~mL}, 0.5 \mathrm{wt} \%)$ was prepared by solubilization in $1.0 \mathrm{wt} \%$ of acetic acid solution ( $\mathrm{pH} \sim 3.53$ ) under constant stirring for 45 minutes, for each of the samples. Following the usual preparation method for $\mathrm{AgNPs}, \mathrm{AgNO}_{3}$ solutions were added to each soluble Cts sample under constant stirring for synthesis of the $\mathrm{AgNO}_{3} / \mathrm{Cts}$ solutions. The aqueous Cts-acetic acid solution thickened after the addition of $\mathrm{AgNO}_{3}$ solution. The Ag content of the samples was 0.5 (A1), 1.0 (A2), 1.5 (A3), 2.0 (A4), and $5.0 \mathrm{~g}$ (A5) Ag/100 g MMT. Constant amounts of MMT were suspended in different volumes of $1 \times 10^{-3} \mathrm{M} \mathrm{AgNO}_{3}$ solution with soluble Cts and stirred for 24 hours at room temperature to obtain the $\mathrm{AgNO}_{3} / \mathrm{MMT} / \mathrm{Cts}$ suspensions. Freshly prepared $\mathrm{NaBH}_{4}$ $\left(4 \times 10^{-2} \mathrm{M}\right)$ solution was then added to the suspensions under continuous stirring to reach a constant $\mathrm{AgNO}_{3} / \mathrm{NaBH}_{4}$ molar ratio (1:4). After the addition of the reducing agent, stirring was continued for another hour. The suspensions of $\mathrm{Ag} / \mathrm{MMT} / \mathrm{Cts} \mathrm{BNCs}$ obtained were then centrifuged, washed four times using double-distilled water to remove the silver ion residue, and dried at $40^{\circ} \mathrm{C}$ under vacuum overnight. All the experiments were conducted at ambient temperature.

\section{Evaluation of antibacterial activity}

The in vitro antibacterial activity of the samples was evaluated by the disc diffusion method using Mueller Hinton agar with determination of inhibition zones, which conformed to the recommended standards of the National Committee for Clinical Laboratory Standards (now known as the Clinical and Laboratory Standards Institute, 2000). E. coli (ATCC 25922), E. coli O157:H7 (ATCC 43895), Pseudomonas aeruginosa (ATCC 10145), S. aureus (ATCC 25923), and MRSA (ATCC 700689) were used for the antibacterial assay. Briefly, $6 \mathrm{~mm}$ sterile paper discs impregnated with $20 \mu \mathrm{L}$ of $\mathrm{Ag} / \mathrm{MMT} / \mathrm{Cts} \mathrm{BNCs}$ (A2, A4, and A5) with different treatment times were suspended in the sterile distilled water and left to dry at $37^{\circ} \mathrm{C}$ for 24 hours under sterile conditions. The bacterial suspension was prepared by making a saline suspension of isolated colonies selected over 18-24 hours of tryptic soy agar plate. The suspension was adjusted to match the tube of 0.5 McFarland turbidity standard using the spectrophotometer at $600 \mathrm{~nm}$, which is equivalent to $1.5 \times 10^{8}$ colony-forming units $/ \mathrm{mL}$. The surface of the Mueller Hinton agar was completely inoculated using a sterile swab, and was then steeped in the prepared suspension of bacterium. Finally, the impregnated discs were placed on the inoculated agar and incubated at $37^{\circ} \mathrm{C}$ for 24 hours. After incubation, the diameter of the growth inhibition zones was measured. Chloramphenicol $30 \mu \mathrm{g}$ and cefotaxime $30 \mu \mathrm{g}$ were used as the positive standards in order to control the sensitivity of the bacteria. All tests were done in triplicate.

\section{Characterization methods}

\section{and instruments}

The prepared Ag/MMT/Cts BNCs were characterized by ultraviolet (UV)-visible spectroscopy, powder X-ray diffraction (PXRD), transmission electron microscopy (TEM), scanning electron microscopy (SEM), energy dispersive X-ray fluorescence spectrometry (EDXRF), inductively coupled plasma-optical emission spectrophotometer (ICP-OES), and Fourier transform infrared (FT-IR) spectroscopy. The UV-visible spectra were recorded over the 300-700 $\mathrm{nm}$ range utilising the Shimadzu H.UV.1650 PC spectrophotometer. The structures of the Ag/MMT/ Cts BNCs produced were examined by powder X-ray diffraction using the Shimadzu PXRD-6000. Changes in the interlamellar spacing of MMT and $\mathrm{Ag} / \mathrm{MMT} / \mathrm{Cts}$ BNCs were also studied by PXRD in the angle range of $2^{\circ}<2 \theta<12^{\circ}$. In addition, the interlamellar spaces were calculated from the PXRD peak positions using Bragg's law. A wavelength $(\lambda)$ of $0.15418 \mathrm{~nm}$ was used for these measurements. The PXRD patterns were recorded at a scan speed of $2^{\circ} \mathrm{min}^{-1}$. TEM observations were carried out on a H-7100 electron microscope (Hitachi, Tokyo, Japan), and the particle size distributions were determined using the UTHSCSA Image Tool program (version 3.00; Dental Diagnostic Science, UTHSCSA, San Antonio, TX). SEM was performed using the Philips XL-30 instrument (Philips, Eindhoven, The Netherlands) to study the morphology of MMT, MMT/Cts, and Ag/MMT/Cts BNCs (A2, A4, and A5). EDXRF was carried out on a EDX-700HS spectrometer (Shimadzu, Osaka, Japan). Elemental analysis of the synthesized AgNPs was quantified using an ICP-OES, model Optima 2000DV (Perkin Elmer, Waltham, MA). Meanwhile, the FT-IR spectra were recorded over the range of $400-4000 \mathrm{~cm}^{-1}$ using the Series 100 Perkin Elmer FT-IR 1650 spectrophotometer. After the reactions, the samples were centrifuged using a high-speed centrifuge machine (Avanti J25; Beckman, Brea, CA). 


\section{Results and discussion}

To prepare the stable AgNPs via the wet chemical reduction method, it was important to choose a suitable stabilizer and reducing agent. In this research, a MMT/Cts suspension was used as the appropriate support for reducing $\mathrm{AgNO}_{3} / \mathrm{MMT} /$ Cts suspension, and using $\mathrm{NaBH}_{4}$ as the strong reducing agent. $\mathrm{AgNO}_{3}$ was reduced by $\mathrm{NaBH}_{4}$ in the presence of MMT hydride with Cts (MMT/Cts), resulting in AgNPs prepared according to the following equation: ${ }^{63}$

$\mathrm{Ag}^{+} / \mathrm{MMT} / \mathrm{Cts}+\mathrm{BH}_{4}^{-}+3 \mathrm{H}_{2} \mathrm{O} \rightarrow \mathrm{Ag}^{0} / \mathrm{MMT} / \mathrm{Cts}+\mathrm{B}(\mathrm{OH})_{3}+3.5 \mathrm{H}_{2} \uparrow$

The schematic illustration of the synthesis of Ag/MMT/ Cts BNCs from $\mathrm{AgNO}_{3} / \mathrm{MMT} / \mathrm{Cts}$ produced using $\mathrm{NaBH}_{4}$ as the chemical reduction agent is shown in Figure 1. Meanwhile, as shown in Figure 2, the MMT and $\mathrm{AgNO}_{3} /$ $\mathrm{MMT} / \mathrm{Cts}$ suspensions (A0) were colorless, but after the addition of the reducing agent to the suspensions, they turned light brown (A1), brown (A2), reddish-brown (A3), and dark brown (A4 and A5), indicating the formation of AgNPs in the MMT/Cts suspensions. The formation of AgNPs was also followed by measuring the surface plasmon resonance bands of the $\mathrm{AgNO}_{3} / \mathrm{MMT} / \mathrm{Cts}$ (A0) and $\mathrm{Ag} / \mathrm{MMT} / \mathrm{Cts} \mathrm{BNCs}$ suspensions (A1-A5) at wavelengths in the $300-700 \mathrm{~nm}$ range (Figure 3). The comparison between the PXRD patterns of MMT, MMT/Cts, and Ag/MMT/Cts BNCs (A1, A2, and A5) in the small angle range of $2 \theta\left(2^{\circ}<2 \theta<12^{\circ}\right)$ indicated the formation of the intercalated AgNPs structure (Figure 4). In addition, the PXRD patterns in the wide angle range of $2 \theta\left(30^{\circ}<2 \theta<80^{\circ}\right)$ were also employed to determine the crystalline structures of the synthesized AgNPs (Figure 5). The TEM images and size distribution of the AgNPs showed that the mean diameter of the nanoparticles ranged from about $6.28 \mathrm{~nm}$ to $9.84 \mathrm{~nm}$ (Figure 6). As shown in Figures 7 and 8 , the SEM images indicated that there were no structural changes between the initial MMT, MMT/Cts, and Ag/MMT/ Cts BNCs (A2, A4, and A5) at different $\mathrm{AgNO}_{3}$ concentrations. In addition, the EDXRF spectra for the MMT, MMT/ Cts and $\mathrm{Ag} / \mathrm{MMT} / \mathrm{Cts}$ BNCs (A2, A4, and A5) confirmed the presence of elemental compounds in MMT, Cts, and AgNPs without any other impurity peaks (Figures 7 and 8). The chemical structures of MMT, MMT/Cts, and Ag/MMT/ Cts BNCs (A2, A4, and A5) were analyzed by FT-IR spectroscopy (Figures 9 and 10). The approximate efficiency gradually increased from A1 to A5, respectively (Table 1). The antibacterial studies showed comparatively similar effects for all samples, as indicated by the inhibition zone test between Cts, MMT/Cts, MMT, $\mathrm{AgNO}_{3} / \mathrm{MMT} / \mathrm{Cts}$ (A0),
A)

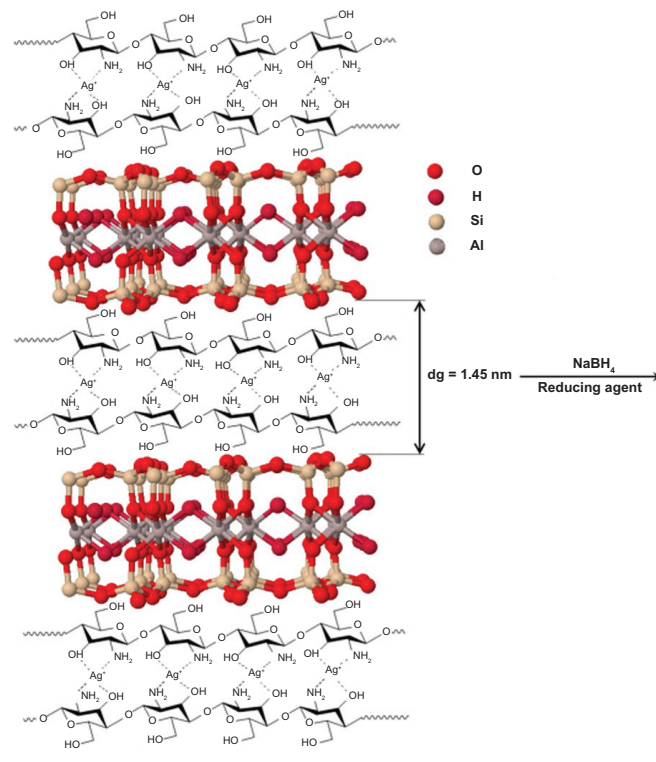

B)

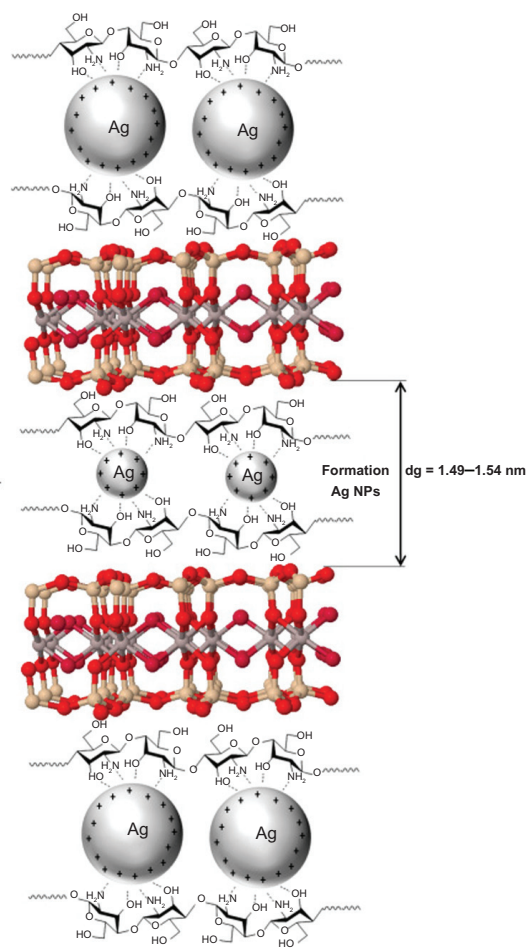

Figure I Schematic illustration of the synthesized silver/montmorillonite/chitosan bionanocomposites from silver nitrate/montmorillonite/chitosan (A0) by a chemical reduction method.

Abbreviations: AgNPs, silver nanoparticles. 


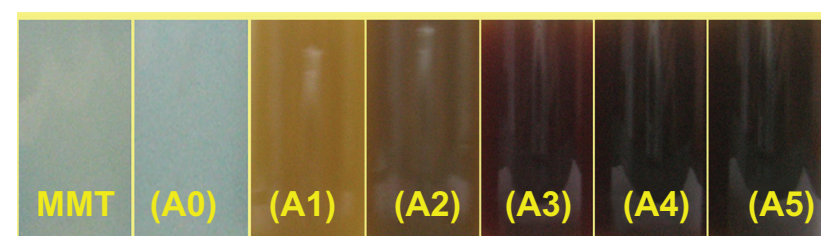

Figure 2 Photograph of montmorillonite/chitosan bionanocomposite suspension (A0) and silver/montmorillonite/chitosan bionanocomposite suspension at different $\mathrm{AgNO}_{3}$ concentrations; (AI) $0.5 \%$, (A2) $1.0 \%$, (A3) $1.5 \%$, (A4) $2.0 \%$, and (A5) $5.0 \%$.

and $\mathrm{Ag} / \mathrm{MMT} / \mathrm{Cts} \mathrm{BNCs}$ (A2, A4, and A5) against different bacteria (Figure 11, Table 2).

\section{Ultraviolet-visible spectroscopy}

The color of the $\mathrm{AgNO}_{3} / \mathrm{MMT} / \mathrm{Cts}$ suspensions through the reduction process using $\mathrm{NaBH}_{4}$ changed from colorless to light brown, brown, reddish-brown, and, finally, dark brown (A1-A5), respectively, which indicated the formation of AgNPs in the MMT/Cts suspension. The silver surface plasmon resonance bands were detected around 391-408 nm (Figure 3). These absorption bands were assumed to correspond to AgNPs smaller than $10 \mathrm{~nm} .{ }^{64}$ While there was no UV-visible absorption of AgNPs before the addition of $\mathrm{NaBH}_{4}$ in A0 (Figure 3), the growth of the plasmon peak at $391 \mathrm{~nm}$ indicated the formation of AgNPs in A1. Furthermore, the gradual increase in the $\mathrm{AgNO}_{3}$ concentration from A1 to A4 also increased the corresponding peak intensities in the wavelength range of 391-403 $\mathrm{nm}$. In A5, the absorption peak due to surface plasmon resonance of $\mathrm{Ag}^{+}$was slightly red-shifted to a higher wavelength $(408 \mathrm{~nm})$, which indicated the increase in size of the AgNPs. ${ }^{65,66}$

\section{Powder X-ray diffraction}

As shown in Figure 4, the original d-spacing $\left(d_{s}\right)$ of MMT $(1.24 \mathrm{~nm})$ and in MMT/Cts, was increased to $1.45 \mathrm{~nm}$ at the small $2 \theta$ angles $\left(2 \theta=7.12^{\circ}\right.$ for MMT and $2 \theta=6.09^{\circ}$ for MMT/Cts) by Cts intercalation. The $\mathrm{d}_{\mathrm{S}}$ in $\mathrm{A} 2$, A4, and

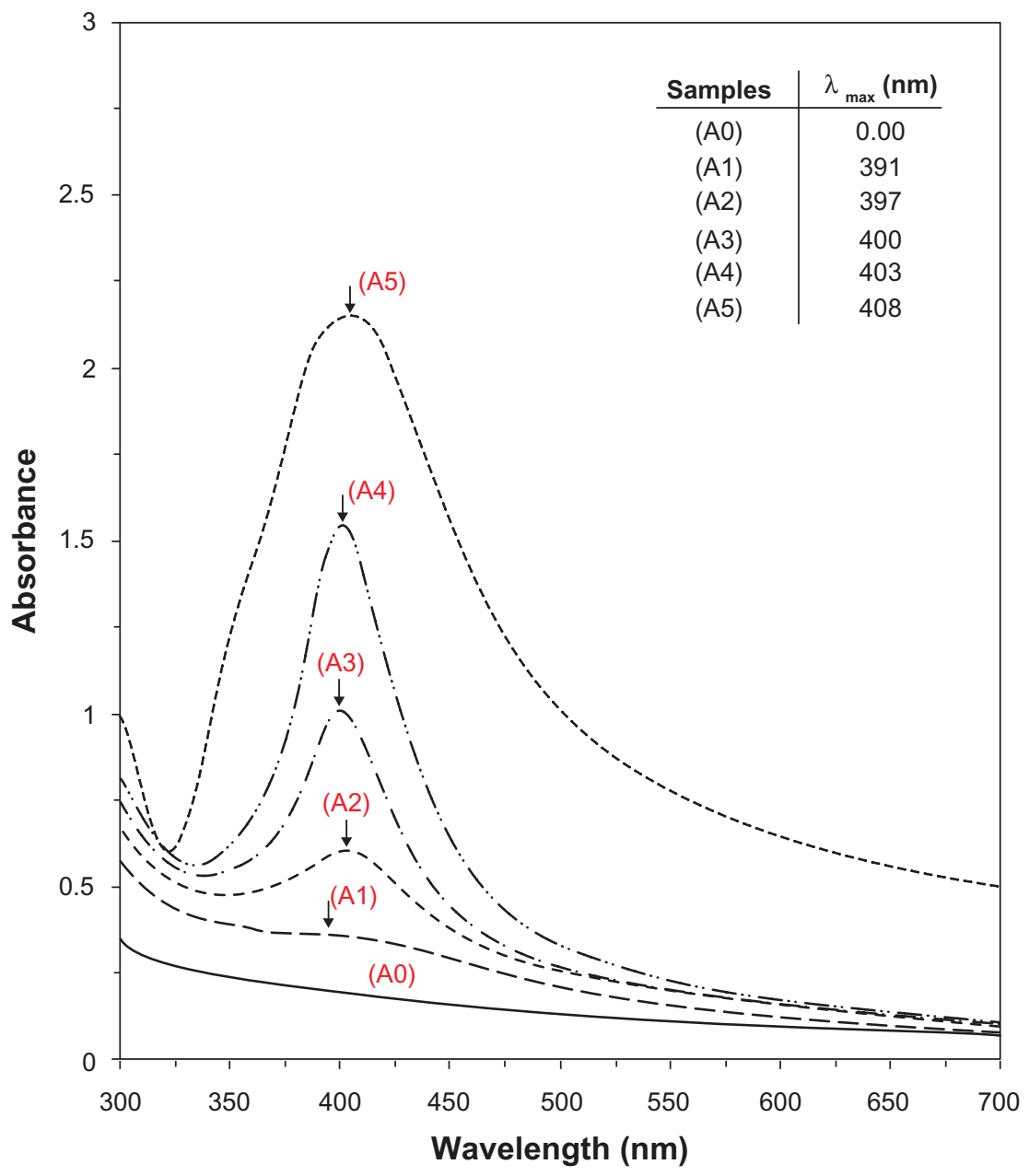

Figure 3 Ultraviolet-visible absorption spectra of silver/montmorillonite/chitosan bionanocomposite suspension for different $\mathrm{AgNO}_{3}$ concentrations: (AI) $0.5 \%$, ( $\left.\mathrm{A} 2\right)$ I.0\%, (A3) $1.5 \%$, (A4) 2.0\%, (A5) 5.0\%, and (A0) silver nitrate/montmorillonite/chitosan bionanocomposite suspension in the absence of sodium borohydride. 


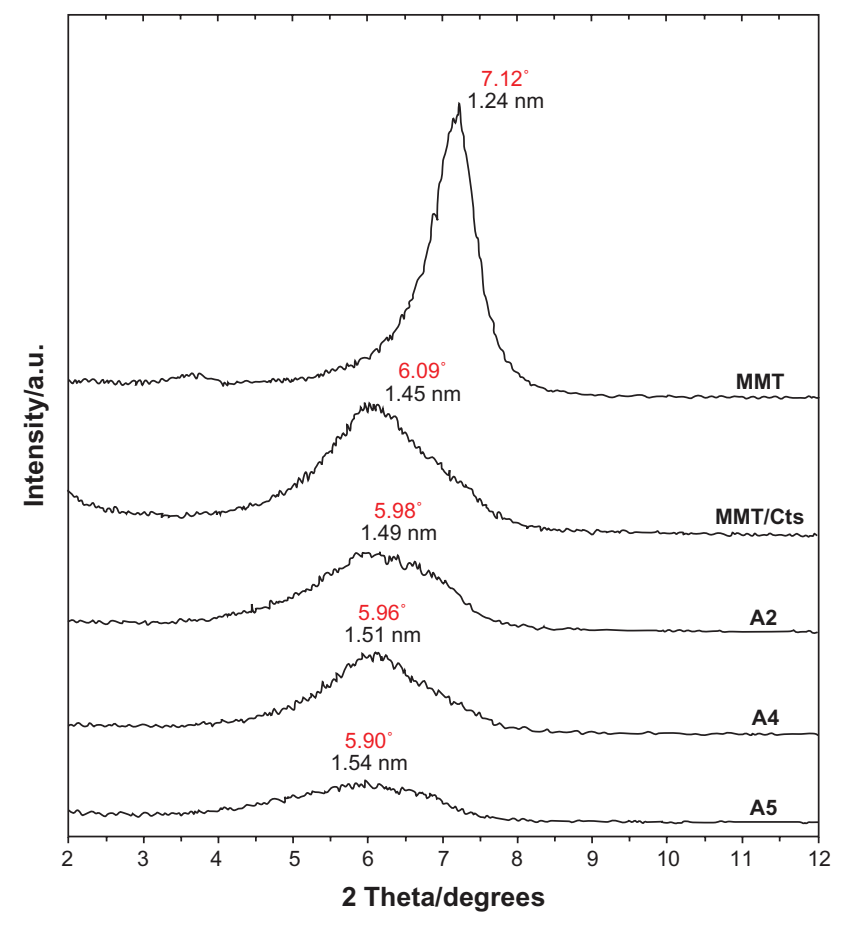

Figure 4 Powder X-ray diffraction patterns of montmorillonite, montmorillonite/ chitosan, and silver/montmorillonite/chitosan bionanocomposites for determination of d-spacing at different $\mathrm{AgNO}_{3}$ concentrations: (A2) 1.0\%, (A4) 2.0\%, and (A5) $5.0 \%$.

Abbreviations: Cts, chitosan; MMT, montmorillonite.

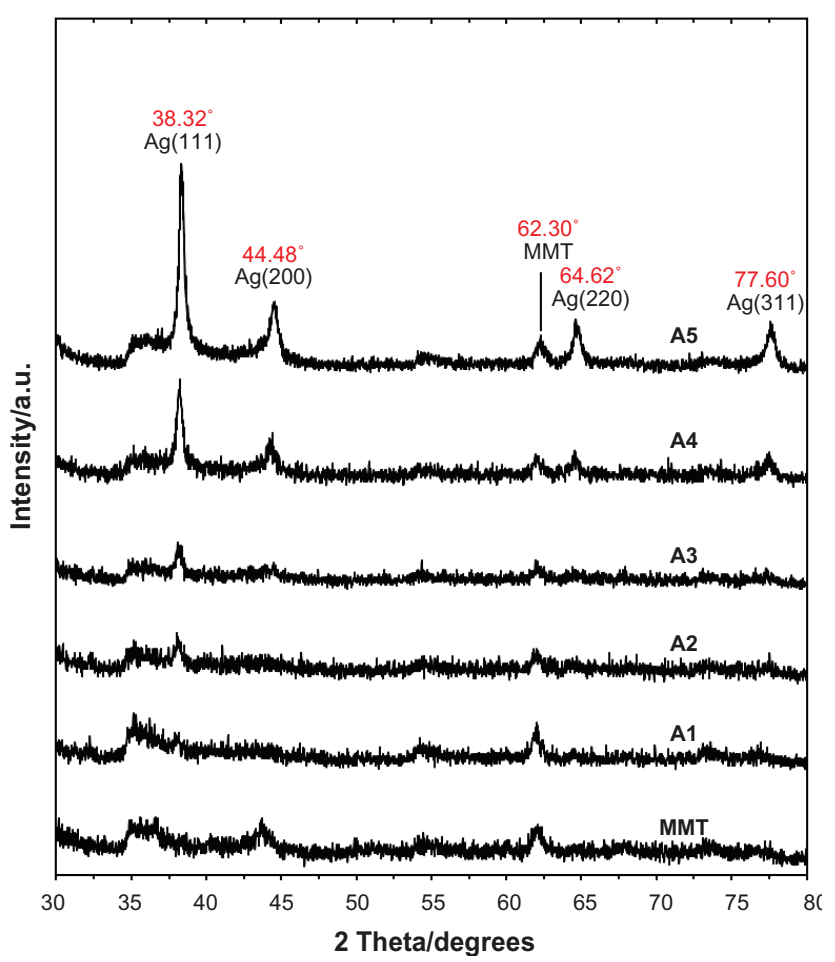

Figure 5 Powder X-ray diffraction patterns of montmorillonite and silver/ montmorillonite/chitosan bionanocomposites for determination of silver crystals at different $\mathrm{AgNO}_{3}$ concentrations: (AI) $0.5 \%$, (A2) $1.0 \%$, (A3) $1.5 \%$, (A4) $2.0 \%$, and (A5) $5.0 \%$.

Abbreviation: MMT, montmorillonite.
A5 also increased gradually from $1.49 \mathrm{~nm}$ to $1.51 \mathrm{~nm}$ and finally to $1.54 \mathrm{~nm}$ at the $2 \theta$ angles $\left(2 \theta=5.98^{\circ}\right.$ [A1], $2 \theta=5.96^{\circ}$ [A4], and $2 \theta=5.90^{\circ}$ [A5]) by $\mathrm{Ag} / \mathrm{Cts}$ intercalation between MMT layers. These $\mathrm{d}_{\mathrm{S}}$ values were direct proof of the intercalation structures. The AgNPs formed at the latter location were the cause of the increase in basal spacing. In these samples, the intensities of the reflections were significantly lower, whereas their half-widths were larger than those of undoped clay minerals, whereby the highly ordered parallel lamellar structure of the mineral was disrupted by metal nanoparticle formation. ${ }^{67}$ In addition, all the Ag/MMT/Cts BNCs (A1-A5) had a similar diffraction profile, and the PXRD peaks at $2 \theta$ of $38.32^{\circ}$, $44.48^{\circ}, 64.62^{\circ}$, and $77.60^{\circ}$ (Figure 5) could be attributed to the $111,200,220$, and 311 crystallographic planes of the face-centered cubic silver crystals, respectively. ${ }^{68}$ For all samples, the main crystalline phase was silver, and no other obvious phases were found as impurities in the PXRD patterns. Moreover, the PXRD peak broadenings of the AgNPs were mostly due to the existing nanosized particles in the BNPs. In addition, there was a characteristic peak at about $2 \theta=62.30^{\circ}$ related to the MMT clay (PXRD Ref No 00-003-0010) as a stable substrate. The intensities of 111 , 200, 220, and 311 reflections due to the AgNP phase were also found to increase along with the increased AgNPs in the solid support matrix content stabilizer (MMT/Cts) by the wet chemical reduction method.

\section{Morphology}

The TEM images and their corresponding particle size distributions for the $\mathrm{Ag} / \mathrm{MMT} / \mathrm{Cts}$ BNCs containing different percentages of AgNPs are shown in Figure 6. The TEM images and their size distributions reveal that the mean diameters and standard deviation of the AgNPs were about $6.28 \pm 3.54,8.29 \pm 3.18$, and $9.84 \pm 2.51 \mathrm{~nm}$ for $1.0 \%$ (A-B), $2.0 \%$ (C-D) and 5.0\% (E-F), respectively. These results showed that the diameters of the AgNPs synthesized by this method depended on the initial $\mathrm{AgNO}_{3}$ concentration. SEM images of the MMT, MMT/Cts, and Ag/MMT/Cts (A2, A4, and A5) are presented in Figures 7 and 8. The surface morphology of MMT demonstrates a layered surface with some large flakes, which is the typical structure for MMT (Figure 7A). The exterior morphology of the MMT/Cts and $\mathrm{Ag} / \mathrm{MMT} / \mathrm{Cts} \mathrm{BNCs}$ (A2, A4, and A5), show layered surfaces with large flakes and without significant morphological differences between them. Furthermore, the external surfaces of $\mathrm{Ag} / \mathrm{MMT} / \mathrm{Cts} \mathrm{BNCs}$ (A2, A4, and A5) gradually become more shiny due to the presence and increase of AgNP amounts 

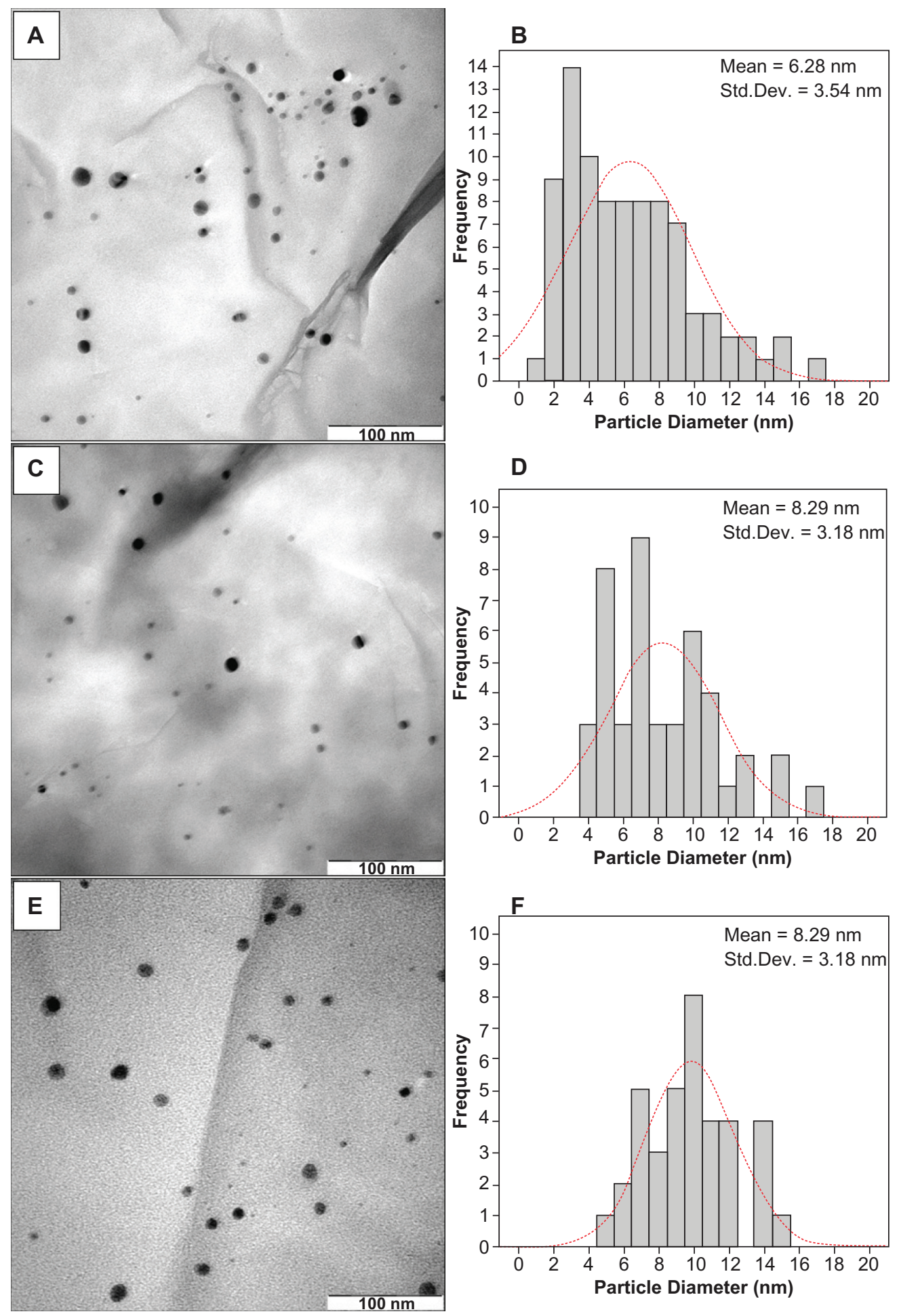

Figure 6 Transmission electron microscopy images and corresponding particle size distribution of silver/montmorillonite/chitosan bionanocomposites at different $\mathrm{AgNO}_{3}$ concentrations: $1.0 \%(\mathbf{A}, \mathbf{B}), 2.0 \%(\mathbf{C}, \mathbf{D})$, and $5.0 \%(\mathbf{E}, \mathbf{F})$.

(Figures 8 A, B, and C). Figure 7 (B, D) shows the EDXRF spectra for the MMT and MMT/Cts. The peaks at around $1.7,2.7,2.9,3.7,4.0,4.5,6.4$, and $7.1 \mathrm{keV}$ are related to the binding energies of MMT, and peaks at around 8.1, 8.7, and $9.6 \mathrm{keV}$ correspond to the binding energies of Cts. In Figure 8D, the peaks around $1.3,3.1,3.3$, and $3.4 \mathrm{keV}$ are related to $\mathrm{Ag}^{+}$ elements in A2, A4, and A5 ${ }^{69}$ In addition, the EDXRF spectra for the MMT, MMT/Cts, and Ag/MMT/Cts BNCs (A2, A4, and A5) confirmed the presence of elemental compounds in the MMT, Cts, and AgNPs without any impurity peaks. 

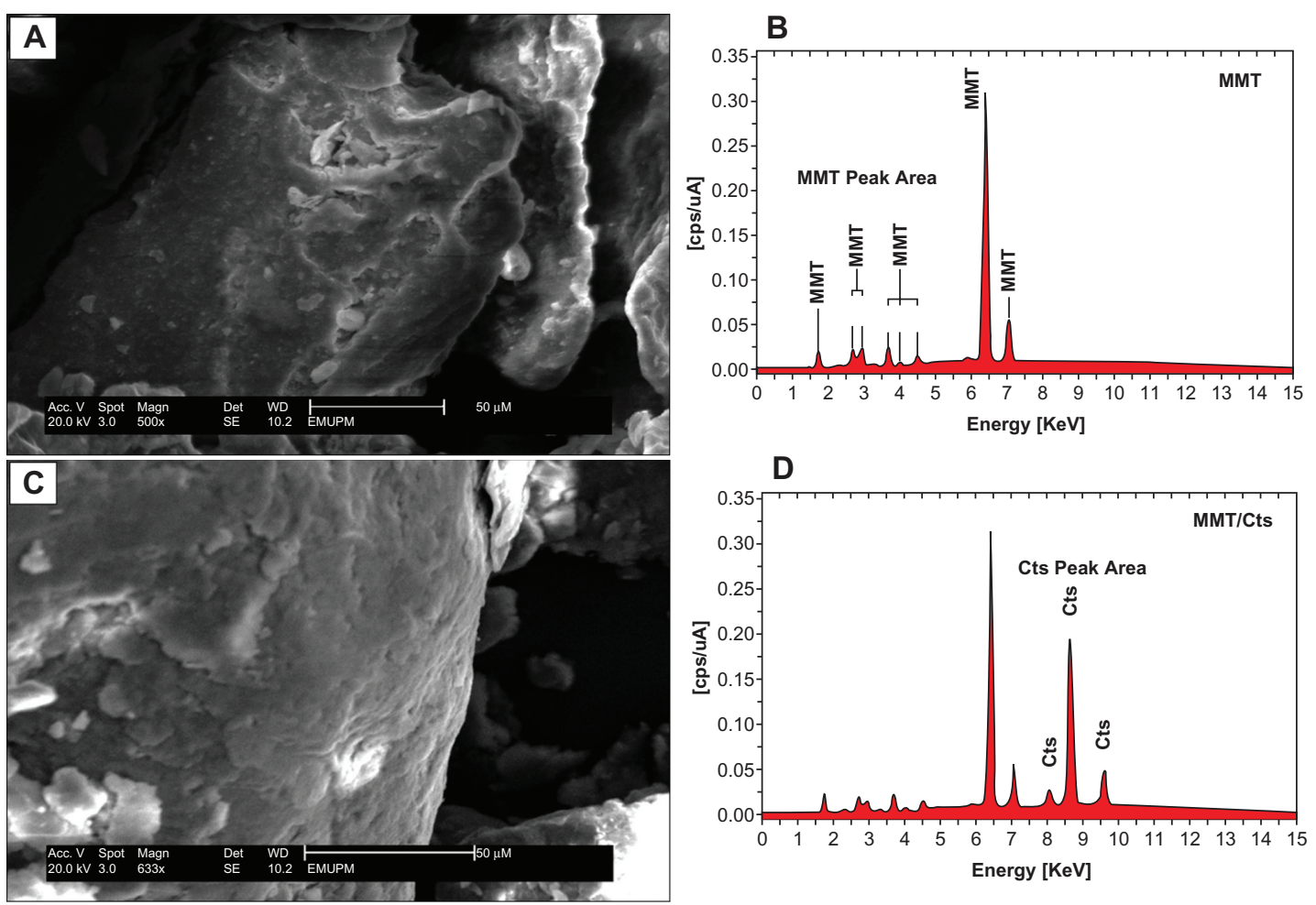

Figure 7 Scanning electron microscopy micrographs and energy dispersive X-ray fluorescence spectra for montmorillonite (A, B) and montmorillonite/chitosan (C, D), respectively. Abbreviations: Cts, chitosan; MMT, montmorillonite.
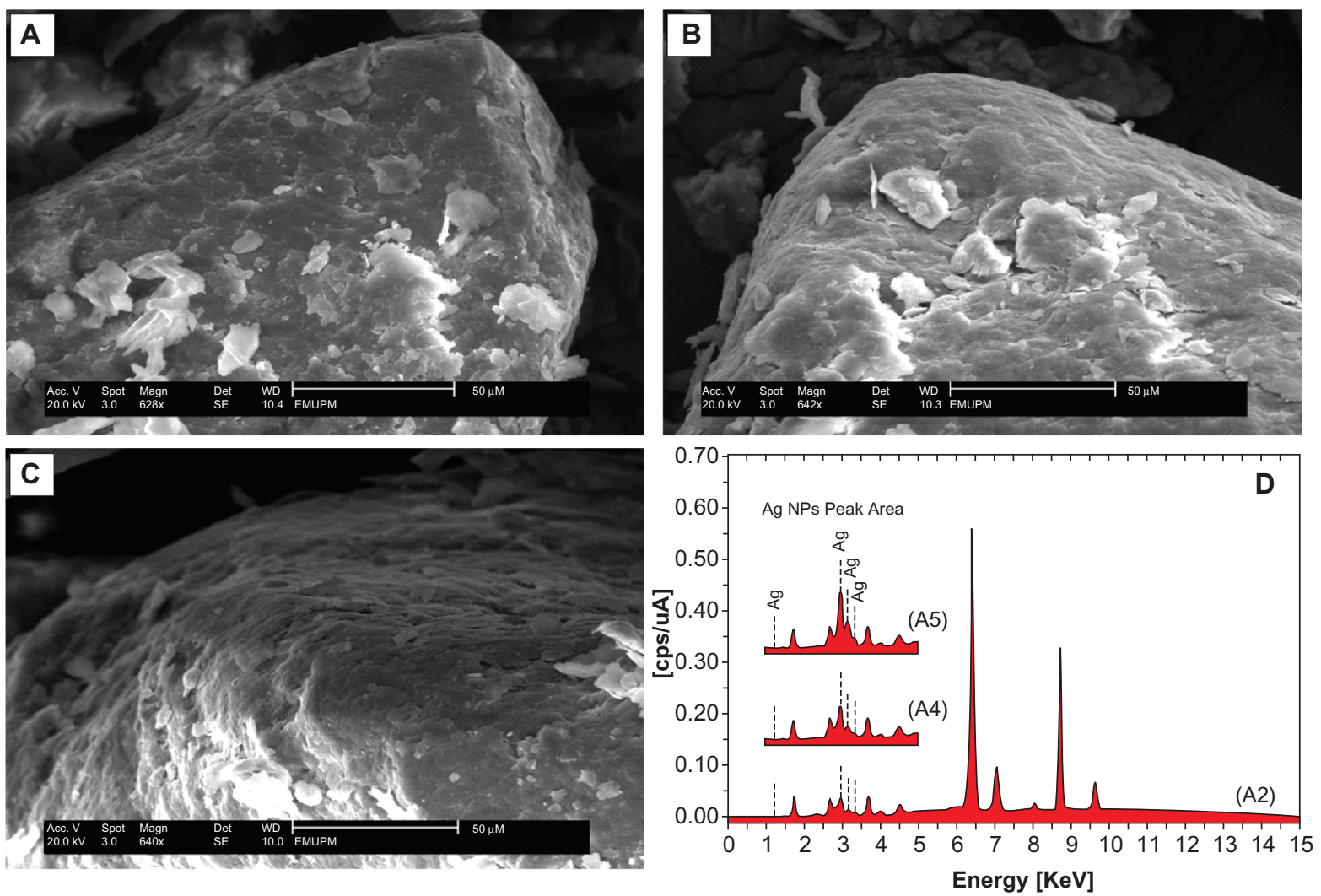

Figure 8 Scanning electron micrographs and energy dispersive X-ray fluorescence spectra, respectively, for the silver/montmorillonite/chitosan bionanocomposites at different $\mathrm{AgNO}_{3}$ concentrations: $1.0 \%$ (A), 2.0\% (B), 5.0\% (C), and (D).

Abbreviation: AgNPs, silver nanoparticles. 


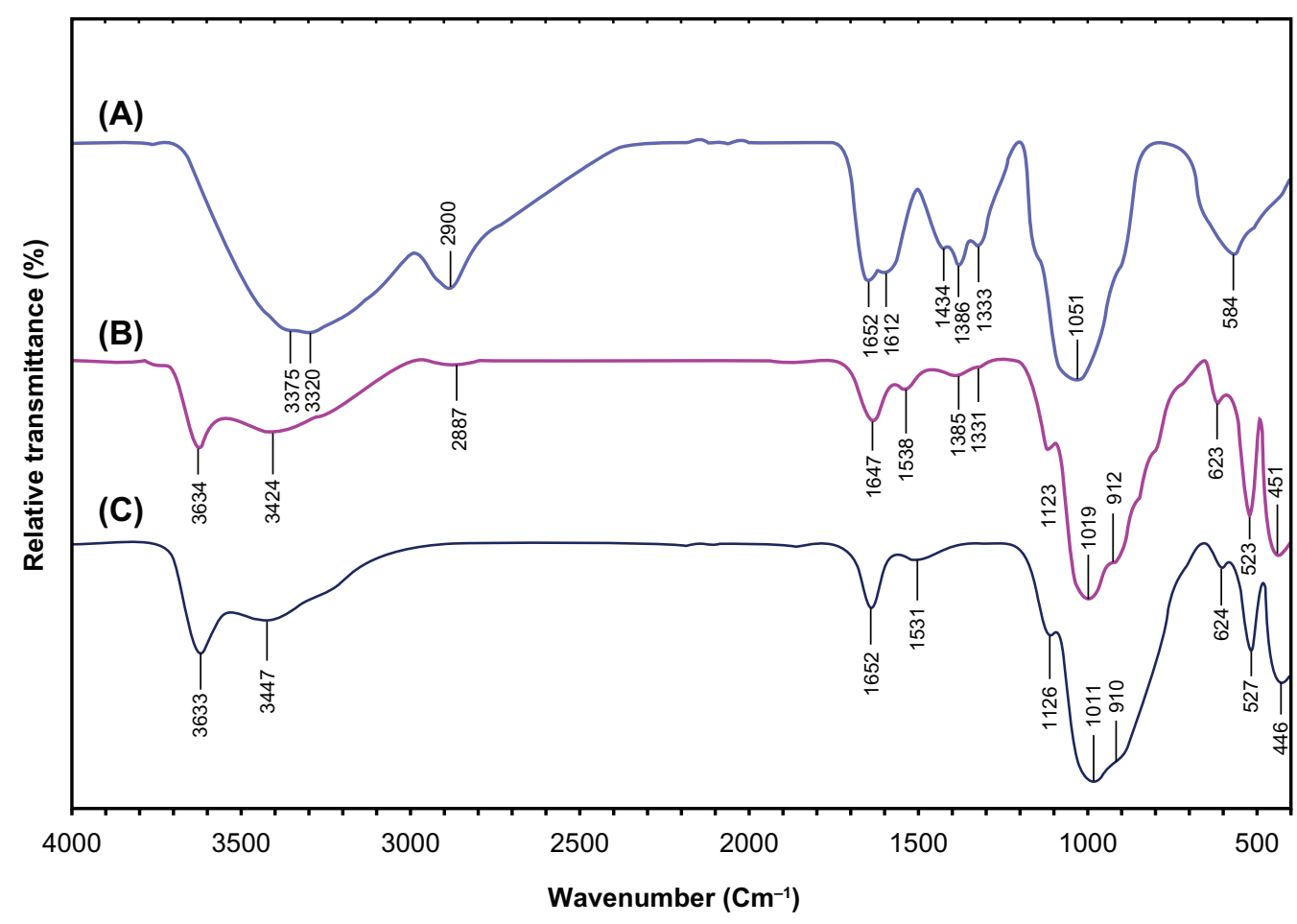

Figure 9 Fourier transform infrared spectra for chitosan (A), montmorillonite/chitosan (B), and montmorillonite (C), respectively.

Figure $8 \mathrm{D}$ also demonstrates that, with the increased percentages of AgNPs in MMT/Cts (1\%, 2\%, and 5\%) and after reduction, the intensity of AgNP peaks in the EDXRF spectra increased. The results indicate that the synthesized BNCs are composed of high-purity Cts and AgNPs.

\section{Chemical analysis by Fourier transform infrared spectroscopy}

The FT-IR spectrum of MMT (Figure 9C) show the vibration bands at $3633 \mathrm{~cm}^{-1}$ for O-H stretching, $3447 \mathrm{~cm}^{-1}$ due to the interlayered O-H stretching (H bonding), at 1652 and $1531 \mathrm{~cm}^{-1}$ for H-O-H bending, 1126, 1011, and $910 \mathrm{~cm}^{-1}$ for Si-O stretching, $624 \mathrm{~cm}^{-1}$ for Al-OH, $910 \mathrm{~cm}^{-1}$ due to (Al, $\mathrm{Mg}$ )-OH vibration modes and 527 and $446 \mathrm{~cm}^{-1}$ for Si-O bending. ${ }^{70}$ The spectrum of Cts (Figure 9A) show peaks at 3375 and $3320 \mathrm{~cm}^{-1}$ due to the overlapping of O-H and N-H stretching bands, ie, $2900 \mathrm{~cm}^{-1}$ for aliphatic C-H stretching, 1652 and $1612 \mathrm{~cm}^{-1}$ for N-H bending, 1434, 1386, and $1333 \mathrm{~cm}^{-1}$ for C-H bending, and $1051 \mathrm{~cm}^{-1}$ for $\mathrm{C}-\mathrm{O}$ stretching. The spectrum of MMT/Cts (Figure 9B) shows a combination of characteristic absorptions due to MMT and the amine groups of $\mathrm{Cts}$. The peaks of the external vibration and interlayered stretching $\mathrm{O}-\mathrm{H}$ groups in MMT and MMT/Cts were relatively constant at 3634, and a little shifted to low wave numbers in $3424 \mathrm{~cm}^{-1}$. On the other hand, the peaks of aliphatic $\mathrm{C}-\mathrm{H}$ and $-\mathrm{NH}_{2}$ groups in pure $\mathrm{Cts}$ at 2900,1652 , and $1612 \mathrm{~cm}^{-1}$ were shifted to 2887,1647 , and
$1538 \mathrm{~cm}^{-1}$ in the MMT/Cts, corresponding to the deformation vibration of the amine group of Cts. ${ }^{71,72}$ These results appeared to be in agreement with the data from PXRD, revealing the intercalation of Cts in the MMT structure.

As shown in Figure 10, there were changes in the spectra of Ag/MMT/Cts BNCs compared with MMT/Cts (Figure 9) and peaks in $\mathrm{A} 2, \mathrm{~A} 4$, and $\mathrm{A} 5$ shifted to lower wave numbers. The FT-IR spectra demonstrated the inflexibility of the silicate layers and the nonbonding chemical interface between the silicate layers and AgNPs in Ag/MMT/Cts BNCs (A2, $\mathrm{A} 4$, and $\mathrm{A} 5$ ). The interactions between the silicate layers of MMT and Cts were related to the peaks at the high and low wave numbers. For example in A2, a peak at $2946 \mathrm{~cm}^{-1}$ is associated with aliphatic C-H stretching, at $1649 \mathrm{~cm}^{-1}$ is related to the overlap Cts peaks in 1652 and $1612 \mathrm{~cm}^{-1}$, with a MMT peak in $1652 \mathrm{~cm}^{-1}$. Moreover, peaks appear in 1448, 1396, and $1330 \mathrm{~cm}^{-1}$ connected with $\mathrm{C}-\mathrm{H}$ bending, similar to the Cts peaks. Broad peaks were due to the presence of van der Waals interactions between the hydroxyl, amine, and $\mathrm{C}-\mathrm{H}$ bending groups of $\mathrm{Cts}$ intercalated to the MMT layers with a partial positive charge on the surface of the AgNPs. ${ }^{61}$ These results confirm that, with the increased amounts of AgNPs in the Ag/MMT/Cts BNCs (A2, A4, and A5), respectively, due to the existence of complexation peaks between the Cts groups and AgNPs, the peaks are shifted to low wave numbers and the peak intensity is increased. 


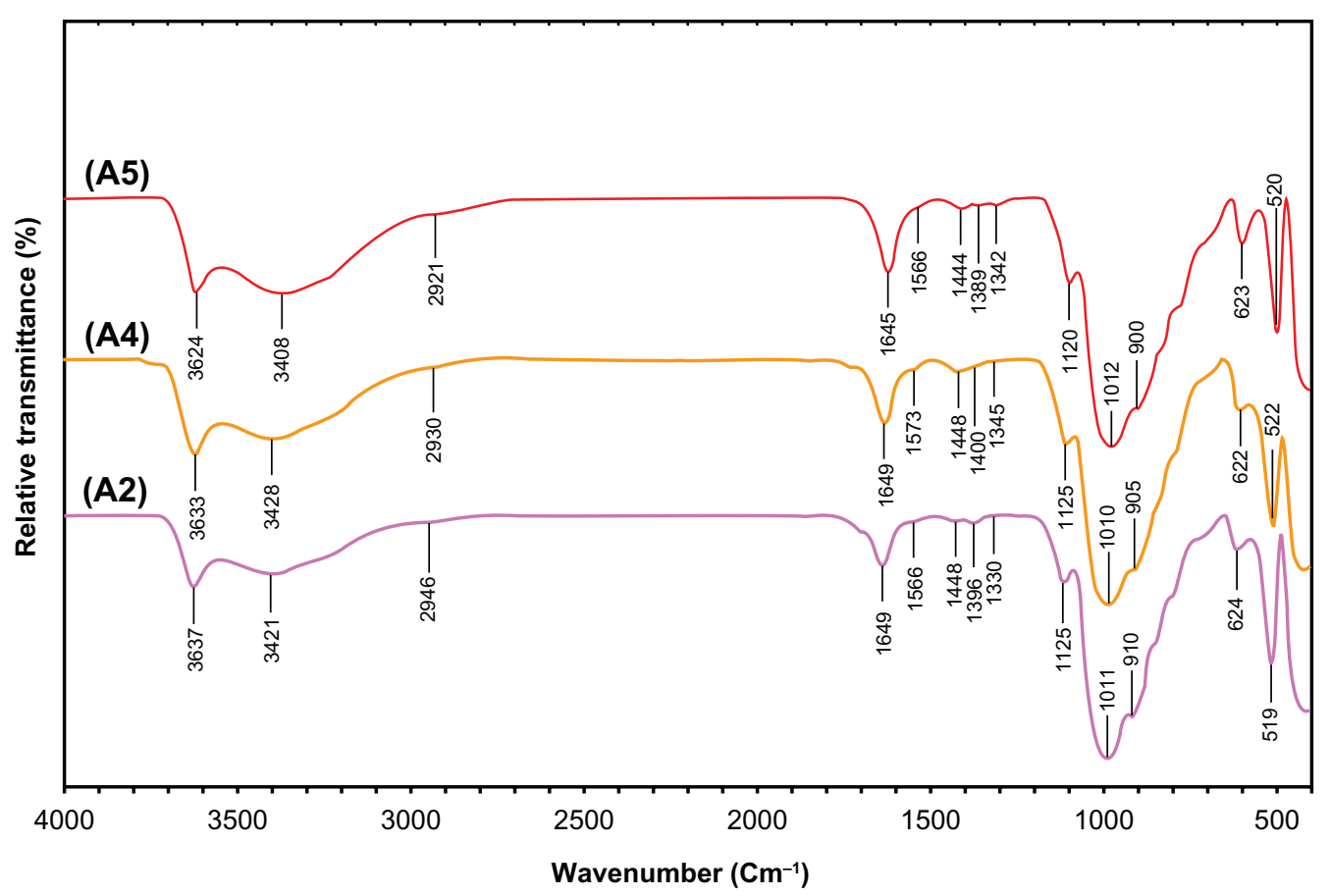

Figure 10 Fourier transform infrared spectra for the silver/montmorillonite/chitosan bionanocomposites at different $\mathrm{AgNO}_{3}$ concentrations: (A2) I.0\% (A), (A4) 2.0\% (B), and (A5) $5.0 \%(\mathbf{C})$.

\section{Inductively coupled plasma-optical emission spectroscopy}

The ICP-OES analyzer was used to determine the approximate efficiency of $\mathrm{AgNO}_{3} / \mathrm{MMT} / \mathrm{Cts}$ suspension reduction by $\mathrm{NaBH}_{4}$ to $\mathrm{Ag} / \mathrm{MMT} / \mathrm{Cts}$ BNCs. A modified digestion method was used to quantify the amount of AgNP conversion to $\mathrm{Ag}^{+}$in the MMT/Cts. An air-dried mass of each $\mathrm{Ag} / \mathrm{MMT} / \mathrm{Cts} \mathrm{BNC}$ sample (A1-A5) was submerged in a solution of $10 \mathrm{~mL}$ of ultrapure reagent grade nitric acid (364576, grade $>90 \%$; Sigma-Aldrich), and $10 \mathrm{~mL}$ of double-distilled water. After the samples were placed over the digestion beakers, the solutions were heated to approximately $80^{\circ} \mathrm{C}$ for 15 minutes and allowed to react. The digestion solutions were allowed to cool in room temperature and then filtered through a glass fiber filter
(Qualitative \#2; Whatman, Florham Park, NJ) and diluted in $100 \mathrm{~mL}$ in volumetric flasks. ${ }^{73}$ After detecting the $\mathrm{Ag}^{+}$ions by ICP-OES spectroscopy, with the increased concentration of $\mathrm{AgNO}_{3}$ in the $\mathrm{MMT} / \mathrm{Cts}$ matrix and then the reduction by the reducing agent, the approximate efficiency gradually decreased from $97.20 \%$ to $95.35 \%, 92.47 \%, 88.53 \%$, and, finally, $83.50 \%$ after A1, A2, A3, A4, and A5, respectively (Table 1). The results from the ICP-OES analysis using a strong reduction agent confirmed the formation of AgNPs in MMT/Cts, which produced high yields.

\section{Antibacterial activity}

Inhibition zone values were obtained for the synthesized $\mathrm{AgNO}_{3} / \mathrm{MMT} / \mathrm{Cts}$ suspension and $\mathrm{Ag} / \mathrm{MMT} / \mathrm{Cts} \mathrm{BNCs}$ (A2, A4, and A5) tested against E. coli, E. coli O157:H7,

Table I Physical properties of silver nanoparticles in silver/montmorillonite/chitosan bionanocomposites synthesised at different $\mathrm{AgNO}_{3}$ concentrations: (AI) 0.5\%, (A2) $1.0 \%$, (A3) $1.5 \%$, (A4) $2.0 \%$, and (A5) $5.0 \%$

\begin{tabular}{llllll}
\hline Samples & $\begin{array}{l}\text { Reaction } \\
\text { volume (Lit) }\end{array}$ & $\lambda$ max $^{\mathrm{a}}$ & Absorbance $^{\mathrm{b}}$ & $\begin{array}{l}\text { Approximated } \\
\text { efficiency }(\%)\end{array}$ & $\begin{array}{l}\text { Ag nanoparticle } \\
\text { size }\end{array}$ \\
\hline AI & & & $97.20 \pm 2.35$ & $5.42 \pm 2.15$ \\
A2 & 0.50 & 391 & 0.44 & $95.35 \pm 2.88$ & $6.28 \pm 3.54$ \\
A3 & 1.00 & 397 & 0.69 & $92.47 \pm 3.72$ & $7.22 \pm 2.96$ \\
A4 & 1.50 & 400 & 1.09 & $88.53 \pm 3.78$ & $8.29 \pm 3.18$ \\
A5 & 2.00 & 403 & 1.63 & $83.50 \pm 5.94$ & $9.84 \pm 2.51$ \\
\hline
\end{tabular}

Notes: ${ }^{a}$ Experiments were repeated three times and averaged; ${ }^{b}$ Data were obtained by multiplying absorbance of the corresponding diluted solutions by their dilution factors when diluted solutions were used for the data; 'Size of silver nanoparticles was determined by measuring diameters of about 100 nanoparticles in transmission electron microscopic image and by averaging them. 


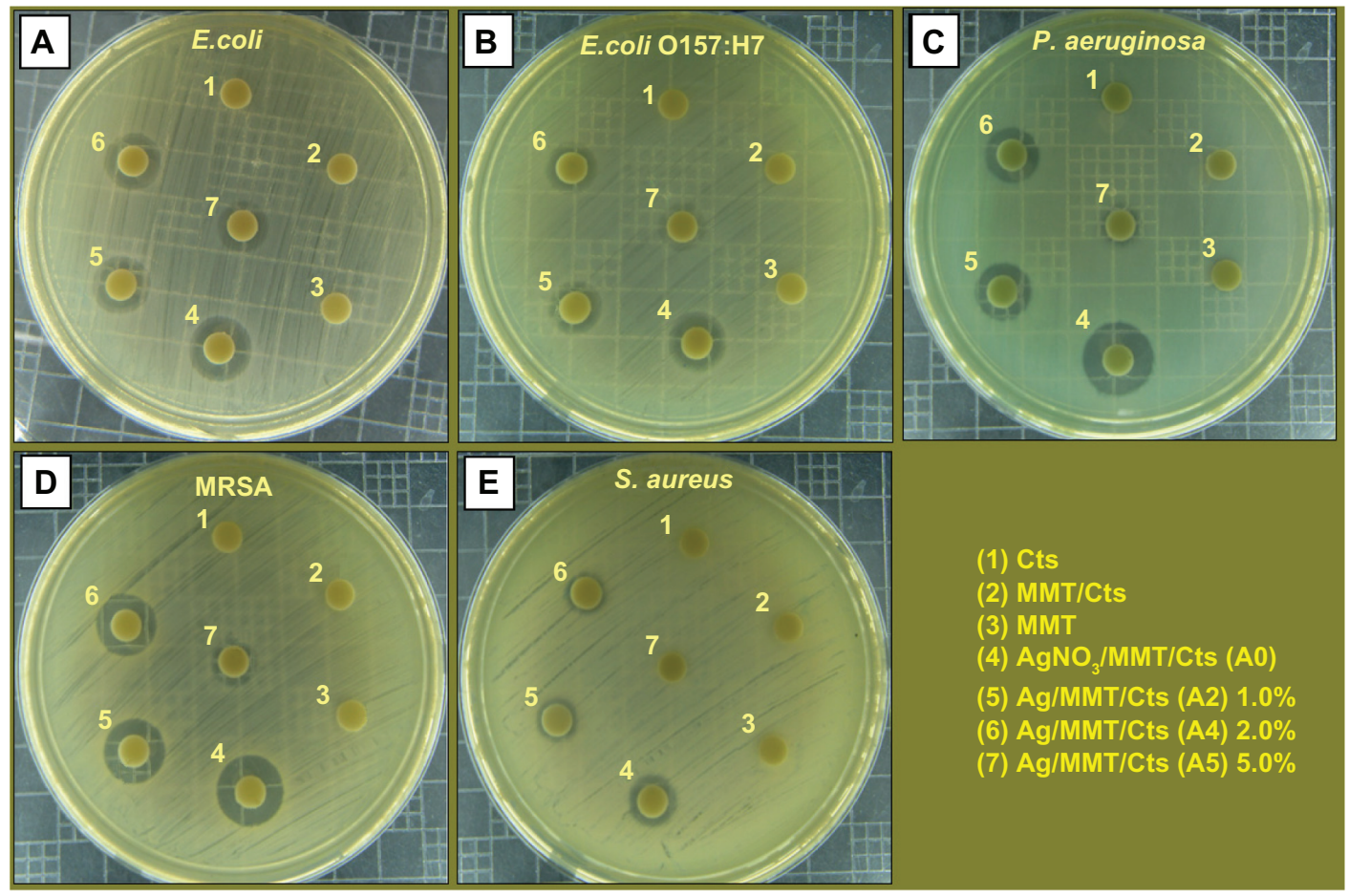

Figure I I Comparison of the inhibition zone test between Gram-negative and Gram-positive bacteria, ie, Escherichia coli (A), E. coli OI57:H7 (B), Pseudomonas aeruginosa (C), Staphylococcus aureus (D), and methicillin-resistant S. aureus (E).

Abbreviations: Cts, chitosan; MMT, montmorillonite.

P. aeruginosa, $S$. aureus, and MRSA. The results and images of the inhibition zones are presented as average values in Table 2 and Figure 11, respectively. Table 2 shows that the $\mathrm{AgNO}_{3}$ and $\mathrm{AgNPs}$ in MMT/Cts suspension had high and similar antibacterial activity against Gram-negative and Gram-positive bacteria. Because of their size, AgNPs can easily reach the nuclear content of bacteria and they show a large and impressive surface area, where contact with bacteria is the greatest. ${ }^{74,75}$ This could be the reason why these nanoparticles have the best antibacterial effect. For solid support systems, some researchers argue that $\mathrm{Ag}^{+}$ions released from the surface of AgNPs are responsible for their antibacterial activity. ${ }^{76,77}$ For aqueous phase systems, the results show that the antibacterial test of $\mathrm{Ag}^{+}$ions is not high at the concentration levels reached by release, and the presence of AgNPs is very important, which reinforces the idea that the larger the surface area, the greater the antibacterial activity. ${ }^{78}$ The diameters of the inhibition zones in agar plates are given in $\mathrm{mm}$. The tests were repeated three times for each treated sample, and the results are presented in Table 2. The suspensions of MMT $(10 \mathrm{mg} / \mathrm{mL})$, soluble Cts $(0.5 \mathrm{mg} / \mathrm{mL})$, and MMT/Cts did not show any antibacterial activity. The $\mathrm{AgNO}_{3} / \mathrm{MMT} /$

Table 2 Average inhibition zone and standard deviation for montmorillonite, chitosan, montmorillonite/chitosan, silver/montmorillonite/ chitosan bionanocomposites (A0), and silver/montmorillonite/chitosan bionanocomposites at different $\mathrm{AgNO}_{3}$ concentrations: (A2) $1.0 \%$, (A4) $2.0 \%$, and (A5) $5.0 \%$

\begin{tabular}{|c|c|c|c|c|c|c|c|c|c|}
\hline \multirow[t]{2}{*}{ Bacteria } & \multicolumn{4}{|c|}{ Inhibition zone (mm) } & \multicolumn{3}{|c|}{ Control negative (mm) } & \multicolumn{2}{|c|}{ Control positive (mm) } \\
\hline & AO & A2 & A4 & A5 & $\begin{array}{l}\text { MMT } \\
(10 \mathrm{mg} / \mathrm{mL})\end{array}$ & $\begin{array}{l}\text { Cts } \\
(0.5 \mathrm{mg} / \mathrm{mL})\end{array}$ & $\begin{array}{l}\text { MMT/ Cts } \\
(10: 0.5 \mathrm{mg} / \mathrm{mL})\end{array}$ & CTX & C \\
\hline E. coli & 11.9 & II.I & 10.9 & 9.7 & NA* & $\mathrm{NA}^{*}$ & $\mathrm{NA}^{*}$ & 21.8 & 16.7 \\
\hline E. coli OI57:H7 & 11.8 & 10.5 & 9.6 & 9.2 & NA & NA & NA & 20.4 & 18.3 \\
\hline P. aeruginosa & 13.9 & 11.3 & 10.5 & 7.4 & NA & NA & NA & 19.3 & 17.6 \\
\hline S. aureus & 9.8 & 8.4 & 7.8 & 6.8 & NA & NA & NA & 23.6 & 16.4 \\
\hline MRSA & 13.2 & 11.9 & II.40 & 9.3 & NA & NA & NA & 18.9 & 15.5 \\
\hline
\end{tabular}

Notes: Mean standard deviation values for the E. coli $\pm 0.93 \mathrm{~mm}$, E. coli OI $57: \mathrm{H} 7 \pm 1.14 \mathrm{~mm}$, P. aeruginosa $\pm 2.69 \mathrm{~mm}, \mathrm{~S}$. aureus \pm I.25 mm, and MRSA \pm I.62 $\mathrm{mm}$ for $\mathrm{A} 0, \mathrm{~A} 2, \mathrm{~A} 4$, and $\mathrm{A} 5$.

Abbreviations: *NA, not appearing; MMT, montmorillonite; Cts, chitosan; E. coli, Escherichia coli; E. coli OI57:H7, Escherichia coli OI57:H7; P. aeruginosa, Pseudomonas aeruginosa; S. aureus, Staphylococcus aureus; MRSA, methicillin-resistant Staphylococcus aureus; CTX, cefotaxime; C, chloramphenicol. 
Cts suspension for all tested bacteria shows high antibacterial activity and, interestingly, these effects in the $\mathrm{Ag} / \mathrm{MMT} / \mathrm{Cts}$ BNCs (A2, A4, and A5) were increased with decreasing size of AgNPs. However, this research also showed that the amounts of AgNPs gradually were increased in the Ag/MMT/ Cts BNCs (A2, A4, and A5), but higher AgNPs loading does not lead to superior antibacterial activity.

\section{Conclusion}

AgNPs were successfully prepared from $\mathrm{AgNO}_{3} / \mathrm{MMT} /$ Cts suspension at different $\mathrm{AgNO}_{3}$ concentrations by using $\mathrm{NaBH}_{4}$ as a chemical reduction agent in the interlamellar space and external layer surface of MMT modified with Cts without any heat treatment or reducing agent. These AgNPs were found to be stabilized by the low molecular weight of Cts. In addition, the distribution size of AgNPs prepared at different concentrations of $\mathrm{AgNO}_{3}$ indicate that larger particle sizes of AgNPs were obtained when the $\mathrm{Ag}^{+}$ion concentration increased. The average diameters of the AgNPs were around 6.28, 8.29, and $9.84 \mathrm{~nm}$ for A2, A4, and A5, respectively. Moreover, the PXRD analysis confirmed that the crystallographic planes of the silver crystals were of the face-centered cubic type. The UV-visible absorption spectra showed the peak characteristics of the surface plasmon resonance bond of AgNPs. SEM images show that the external morphology for MMT, MMT/Cts and Ag/MMT/Cts BNCs (A2, A4, and A5) have layered surfaces with large flakes, with no noteworthy morphological distinctions between them. Also, due to the presence of AgNPs in the external and internal surfaces of $\mathrm{Ag} / \mathrm{MMT} / \mathrm{Cts} \mathrm{BNCs}$, these layers become shiny. EDXRF spectra confirmed the presence of elemental compounds in the MMT, Cts, and AgNPs without any contamination peaks. The antibacterial activities of Ag/MMT/Cts BNCs at the different AgNP particle sizes showed strong antibacterial activity against Gram-positive and Gram-negative bacteria. These results show that the antibacterial resistance of AgNPs in MMT/Cts can be modified according to the size of AgNPs, and decreases with increased particle size. Further studies are required to investigate the bactericidal effects of $\mathrm{Ag} / \mathrm{MMT} /$ Cts BNCs against different types of bacteria for potential widening of their applications, such as in surgical devices and in drug-delivery vehicles.

\section{Acknowledgments}

The authors are grateful to the staff of the Department of Chemistry, Universiti Putra Malaysia, for their help with this research, and to the Institute of Bioscience, Universiti Putra Malaysia, for technical assistance.

\section{Disclosure}

The authors have no conflicts of interest to disclose in this work.

\section{References}

1. Carotenuto G, Pepe GP, Nicolais L. Preparation and characterization of nano-sized Ag/PVP composites for optical applications. Eur Phys J B. 2000;16:11-17.

2. Stathatos E, Lianos P. Photocatalytically deposited silver nanoparticles on mesoporous $\mathrm{TiO}_{2}$ films. Langmuir. 2000;16:2398-2400.

3. Kyriacou SV, Brownlow WJ, Xu XN. Using nanoparticle optics assay for direct observation of the function of antimicrobial agents in single live bacterial cells. Biochemistry. 2004;43:140-147.

4. Feng X, Ma H, Huang S, et al. Aqueous-organic phase-transfer of highly stable gold, silver, and platinum nanoparticles and new route for fabrication of gold nanofilms at the oil/water interface and on solid supports. J Phys Chem B. 2006:110:12311-12317.

5. Choi S, Kim KS, Yeon SH, et al. Fabrication of silver nanoparticles via self-regulated reduction by 1-(2-hydroxyethyl)-3methylimidazolium tetrafluoroborate. Korean J Chem Eng. 2007;24: 856-859.

6. Kawashita M, Tsuneyama S, Mijaji F, et al. Antibacterial silvercontaining silica glass prepared by the sol-gel method. Biomaterials. 2000;21:393-398.

7. Gauger A, Mempel M, Schekatz A, et al. Silver-coated textiles reduce Staphylococcus aureus colonization in patients with atopic eczema. Dermatology. 2003;207:15-21.

8. Lee HJ, Jeong SH. Bacteriostasis and skin innoxiousness of nanosize silver colloids on textile fabrics. Text Res J. 2005;75: $551-556$.

9. Ohashi S, Saku S, Yamamoto KJ. Antibacterial activity of silver inorganic agent YDA filler. Oral Rehabil. 2004;31:364-367.

10. Rupp ME, Fitzgerald T, Marion N, et al. Effect of silver-coated urinary catheters: Efficacy, cost-effectiveness, and antimicrobial resistance. Am J Infect Control. 2004;32:445-450.

11. Samuel U, Guggenbichler JP. Prevention of catheter-related infections: The potential of a new nano-silver impregnated catheter. Int $J$ Antimicrob Agents. 2004;23:75-78.

12. Strathmann M, Wingender J. Use of an oxonol dye in combination with confocal laser scanning microscopy to monitor damage to Staphylococcus aureus cells during colonisation of silver-coated vascular grafts. Int J Antimicrob Agents. 2004;24:234-240.

13. Bosetti M, Masse A, Tobin E, et al. Silver coated materials for external fixation devices: In vitro biocompatibility and genotoxicity. Biomaterials. 2002;23:887-892.

14. Alt V, Bechert T, Steinrücke P, et al. An in vitro assessment of the antibacterial properties and cytotoxicity of nanoparticulate silver bone cement. Biomaterials. 2004;25:4383-4391.

15. Ulkur E, Oncul O, Karagoz H, et al. Comparison of silver-coated dressing $\left(\right.$ Acticoat $\left.{ }^{\mathrm{TM}}\right)$, chlorhexidine acetate $0.5 \%$ (Bactigrass $\left.^{\circledR}\right)$, and fusidic acid $2 \%$ (Fucidin $^{\circledR}$ ) for topical antibacterial effect in methicillin-resistant staphylococci-contaminated, full-skin thickness rat burn wounds. Burns. 2005;31:874-877.

16. Parikh DV, Fink T, Rajasekharan K, et al. Antimicrobial silver/ sodium carboxymethyl cotton dressings for burn wounds. Text Res J. 2005;75:134-138.

17. Gosheger G, Hardes J, Ahrens H, et al. Silver-coated megaendoprostheses in a rabbit model an analysis of the infection rate and toxicological side effects. Biomaterials. 2004;25:5547-5556.

18. Chou WL, Yu DG, Yang MC. The preparation and characterization of silver-loading cellulose acetate hollow fiber membrane for water treatment. Polym Adv Technol. 2005;16:600-607.

19. Yuranova T, Rincon AG, Bozzi A, et al. Antibacterial textiles prepared by RF-plasma and vacuum-UV mediated deposition of silver. Photochem Photobiol A. 2003;161:27-34. 
20. Jeong SH, Yeo SY, Yi SC. The effect of filler particle size on the antibacterial properties of compounded polymer/silver fibers. J Mater Sci. 2005;40:5407-5411.

21. Sun RWY, Chen R, Chung NPY, et al. Silver nanoparticles fabricated in Hepes buffer exhibit cytoprotective activities toward HIV-1 infected cells. Chem Commun. 2005;40:5059-5061.

22. Matijevic E. Preparation and properties of uniform size colloids. Chem Mater. 1993;5:412-426.

23. Nickel U, Castell AZ, Poppl K, et al. A silver colloid produced by reduction with hydrazine as support for highly sensitive surface-enhanced raman spectroscopy. Langmuir. 2000;16:9087-9091.

24. Leopold N, Lendl BJ. A new method for fast preparation of highly surface-enhanced raman scattering (SERS) active silver colloids at room temperature by reduction of silver nitrate with hydroxylamine hydrochloride. Phys Chem B. 2003;107:5723-5727.

25. Khanna PK, Subbarao VVVS. Nanosized silver powder via reduction of silver nitrate by sodium formaldehydesulfoxylate in acidic $\mathrm{pH}$ medium. Mater Lett. 2003;57:2242-2245.

26. Sondi I, Goia DV, Matijevic EJJ. Preparation of highly concentrated stable dispersions of uniform silver nanoparticles. Colloid Interface Sci. 2003;260:75-81.

27. Morones JR, Elechiguerra JL, Camacho A, et al. The bactericidal effect of silver nanoparticles. Nanotechnology. 2005;16:2346-2353.

28. Baker C, Pradhan A, Pakstis L, et al. Synthesis and antibacterial properties of silver nanoparticles. Nanosci Nanotechnol. 2005;5:244-249.

29. Yong KT, Sahoo Y, Swihart MT, et al. Synthesis and plasmonic properties of silver and gold nanoshells on polystyrene cores of different size and of gold-silver core-shell nanostructures. Colloids and Surfaces A. 2006;290:89-105.

30. Shameli K, Ahmad MB, Yunus WMZW, et al. Silver/poly(lactic acid) nanocomposites: Preparation, characterization, and antibacterial activity. Int J Nanomedicine. 2010;5:573-579.

31. Shen J, Shi M, Li N, et al. Facile synthesis and application of Ag-chemically converted graphene nanocomposites. Nano Res. 2010;3:339-349.

32. Wu ML, Chen DH, Huang TC. Evidence for seed-mediated nucleation in the chemical reduction of gold salts to gold nanoparticles. Chem Mater. 2001;13:2313-2322.

33. Underhill RS, Liu G. Preparation and performance of Pd particles encapsulated in block copolymer nanospheres as a hydrogenation catalyst. Chem Mater. 2000;12:3633-3641.

34. Torigoe K, Suzuki A, Esumi K. Au (III)-PAMAM interaction and formation of Au-PAMAM nanocomposites in ethyl acetate. J Colloid Interface Sci. 2001;241:346-356.

35. Henglein A, Giersig M. Reduction of Pt (II) by $\mathrm{H}_{2}$ : Effects of citrate and $\mathrm{NaOH}$ and reaction mechanism. J Phys Chem B. 2000;104:6767-6772.

36. Mayer ABR, Grebner W, Wannemacher R. Preparation of silver-latex composites. J Phys Chem B. 2000;104:7278-7285.

37. Han MY, Quek CH, Huang W, et al. A simple and effective chemical route for the preparation of uniform nonaqueous gold colloids. Chem Mater. 1999;11:1144-1147.

38. Yin Y, Li Z-Y, Zhong Z, et al. Synthesis and characterization of stable aqueous dispersions of silver nanoparticles through the Tollens process. J Mater Chem. 2002;12:522-527.

39. Wang Y, Ren J, Deng K, et al. Preparation of tractable platinum, rhodium, and ruthenium nanoclusters with small particle size in organic media. Chem Mater. 2000;12:1622-1627.

40. Pathak S, Greci MT, Kwong RC, et al. Synthesis and applications of palladium-coated poly(vinylpyridine) nanospheres. Chem Mater. 2000;12:1985-1989.

41. Tan Y, Li Y, Zhu D. Preparation of silver nanocrystals in the presence of aniline. J Colloid Interface Sci. 2003;258:244-251.

42. Wang J, Neoh KG, Kang ET. Preparation of nanosized metallic particles in polyaniline. J Colloid Interface Sci. 2001;239:78-86

43. Lim B, Jiang M, Yu T, et al. Nucleation and growth mechanisms for $\mathrm{Pd}-\mathrm{Pt}$ bimetallic nanodendrites and their electrocatalytic properties. Nano Res. 2010;3:69-80.
44. Changa JH, Ana YU, Cho D, et al. Poly (lactic acid) nanocomposites: Comparison of their properties with montmorillonite and synthetic mica (II). Polymer. 2003;44:3715-3720.

45. Chang JH, An YU, Sur GS. Poly (lactic acid) nanocomposites with various organoclays. I. Thermomechanical properties, morphology, and gas permeability. J Polym Sci B Pol Phys. 2003;41: 94-103.

46. Giannelis EP, Krishnamoorti R, Manias E. Polymer-silicate nanocomposites: Model systems for confined polymers and polymer brushes. Adv Polym Sci. 1999;138:107-147.

47. Ramsay JDF, Swanton SW, Bunce JJ. Swelling and dispersion of smectite caly colloids: Determination of structure by neutron diffraction and small-angle neutron scattering. J Chem Soc Faraday Trans. 1999;86:3919-3926.

48. Ahmad MB, Shameli K, Darroudi M, et al. Synthesis and characterization of silver/clay nanocomposites by chemical reduction method. $\mathrm{Am}$ J Appl Sci. 2009;6:1909-1914.

49. Gao Y, Yunzhao Y. Deposition of silver nanoparticles on montmorillonite platelets by chemical plating. J Mater Sci. 2002;37:5083-5087.

50. Wang S-F, Shen L, Zhang W-D, et al. Preparation and mechanical properties chitosan/carbon nanotubes composites. Biomacromolecules. 2005;6:3067-3072.

51. Darder M, Colilla M, Ruiz-Hitzky E. Chitosan-clay nanocomposites: Application as electrochemical sensors. Appl Clay Sci. 2005;28:199-208.

52. Zhou NL, Liu Y, Li L, et al. A new nanocomposite biomedical material of polymer/clay-Cts-Ag nanocomposites. Curr Appl Phys. 2007; 7S1:58-62.

53. Ahmad MB, Shameli K, Darroudi M, et al. Synthesis and antibacterial activity of silver/montmorillonite nanocomposites. Res J Biol Sci. 2009;4:1032-1036.

54. O'Hanlon SJ, Enright MC. A novel bactericidal fabric coating with potent in vitro activity against methicillin-resistant Staphylococcus aureus (MRSA). Int J Antimicrob Agents. 2009;33: $427-431$.

55. Holtz RD, Filho AGS, Brocchi M, Martins D, Durán N, Alves OL. Development of nanostructured silver vanadates decorated with silver nanoparticles as a novel antibacterial agent. Nanotechnology. 2010;21:1-8.

56. Lara HH, Ayala-Nuñez NV, Ixtepan-Turrent L, RodriguezPadilla C. Mode of antiviral action of silver nanoparticles against HIV-1. J Nanobiotechnology. 2010;8:1-10.

57. Medina-Ramirez I, Bashirb S, Luo Z, et al. Green synthesis and characterization of polymer-stabilized silver nanoparticles. Colloids Surf B Biointerfaces. 2009;73:185-191.

58. Shameli K, Ahmad MB, Yunus WMZW, et al. Synthesis and characterization of silver/talc nanocomposites using the wet chemical reduction method. Int J Nanomedicine. 2010;5:743-751.

59. Darroudi M, Ahmad MB, Shameli K, et al. Synthesis and characterization of UV-irradiated silver/montmorillonite nanocomposites. Solid State Sci. 2009;11:1621-1624.

60. Ahmad MB, Shameli K, Yunus WMZW, et al. Synthesis and characterization of silver/clay/starch bionanocomposites by green method. Aust J Basic Appl Sci. 2010;4:2158-2165.

61. Shameli K, Ahmad MB, Yunus WMZW, et al. Green synthesis of silver/ montmorillonite/chitosan bionanocomposites using the UV irradiation method and evaluation of antibacterial activity. Int $J$ Nanomedicine. 2010;5:875-887.

62. Ahmad MB, Shameli K, Darroudi M, et al. Synthesis and characterization of silver/clay/chitosan bionanocomposites by UV-irradiation method. Am J Appl Sci. 2009;6:2030-2035.

63. Song KC, Lee MS, Park TS, et al. Preparation of colloidal silver nanoparticles by chemical reduction method. Korean J Chem Eng. 2009;26:153-155.

64. Aihara N, Torigoe K, Esumi K. Preparation and characterization of gold and silver nanoparticles in layered laponite suspensions. Langmuir. $1998 ; 14: 4945-4949$. 
65. Xu G-N, Qiao X-L, Qiu X-L, et al. Preparation and characterization of stable monodisperse silver nanoparticles via photoreduction. Colloids and Surfaces A. 2008;320:222-226.

66. Liu Z, Wang H, Wang LX. Red shift of plasmon resonance frequency due to the interacting Ag nanoparticle embedded in single crystal $\mathrm{SiO}_{2}$ by implantation. Appl Phys Lett. 1998;72:1823-1825.

67. Patakfalvi RA, Oszka A, Dekany I. Synthesis and characterization of silver nanoparticles/kaolinite composites. Colloids Surf A Physicochem Eng Asp. 2003;220:45-54.

68. Shin HS, Yang HJ, Kim SB, et al. Mechanism of growth of colloidal silver nanoparticles stabilized by polyvinyl pyrrolidone in $\gamma$-irradiated silver nitrate solution. J Colloid Interface Sci. 2004;274:89-94.

69. Bar H, Bhui DK, Sahoo GP, et al. Green synthesis of silver nanoparticles using latex of Jatropha curcas. Colloids and Surf A. 2009;339: 134-139.

70. Alemdar A, Güngör N, Ece OI, et al. The rheological properties and characterization of bentonite dispersions in the presence of non-ionic polymer PEG. J Mater Sci. 2005;40:171-177.

71. Günister E, Pestreli D, Ünlü $\mathrm{CH}$, et al. Synthesis and characterization of chitosan-MMT biocomposite systems. Carbohyd Polym. 2007;67:358-365
72. Darder M, Colilla M, Ruiz-Hitzky E. Biopolymer-clay nanocomposites based on chitosan intercalated in montmorillonite. Chem Mater. 2003; 15:3774-3780.

73. Benn TM, Westerhoff P. Nanoparticle silver released into water from commercially available sock fabrics. Environ Sci Technol. 2008;42:4133-4139.

74. Chudasama B, Vala AV, Andhariya N, et al. Enhanced antibacterial activity of bifunctional $\mathrm{Fe}_{3} \mathrm{O}_{4}$ core-shell nanostructures. Nano Res. 2009;2:955-965.

75. Chen SF, Li JP, Qian K, et al. Large scale photochemical synthesis of $\mathrm{M} 2 \mathrm{TiO} 2$ nanocomposites $(\mathrm{M}=\mathrm{Ag}, \mathrm{Pd}, \mathrm{Au}, \mathrm{Pt})$ and their optical properties, $\mathrm{CO}$ oxidation performance, and antibacterial effect. Nano Res. 2010;3:244-255.

76. Morones JR, Elechiguerra JL, Camacho A, et al. The bactericidal effect of silver nanoparticles. Nanotechnology. 2005;16:2346-2353.

77. Lee D, Cohen RE, Rubner MF. Antibacterial properties of Ag nanoparticle loaded multilayers and formation of magnetically directed antibacterial microparticles. Langmuir. 2005;21:9651-9659.

78. Jeong SH, Hwnag YH, Yi SC. Antibacterial properties of padded PP/ PE nonwovens incorporating nano-sized silver colloids. J Mater Sci. 2005;40:5413-5418.
International Journal of Nanomedicine

\section{Publish your work in this journal}

The International Journal of Nanomedicine is an international, peerreviewed journal focusing on the application of nanotechnology in diagnostics, therapeutics, and drug delivery systems throughout the biomedical field. This journal is indexed on PubMed Central, MedLine, CAS, SciSearch ${ }^{\circledR}$, Current Contents ${ }^{\circledR} /$ Clinical Medicine,

\section{Dovepress}

Journal Citation Reports/Science Edition, EMBase, Scopus and the Elsevier Bibliographic databases. The manuscript management system is completely online and includes a very quick and fair peer-review system, which is all easy to use. Visit http://www.dovepress.com/ testimonials.php to read real quotes from published authors. 